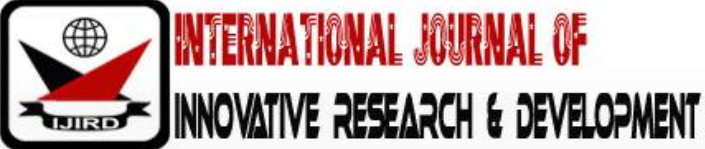

ISSN 2278 - 0211 (Online)

\section{Source-Based Academic Writing through Paraphrasing and Summarizing: Students' Perceptions and Practices}

\author{
Huan Buu Nguyen \\ School of Foreign Languages, Can Tho University, Vietnam \\ Lan Anh Thi Nguyen \\ College of Economics, Can Tho University, Vietnam
}

\begin{abstract}
:
This paper reports a descriptive study to examine students' academic writing performance and their perceptions about source-based writing, particularly through paraphrasing and summarizing. This paper draws on data collected as part of a larger project including questionnaire, writing tests, and interviews. The findings reveal that students perceived the role source-based academic writing plays in the English for Specific Purposes classes; however, their writing performance in paraphrasing and summarizing still remains at an average level. The qualitative analysis from interviews indicates that students held positive perceptions about the source-based writing, namely their understanding of how paraphrasing and summarizing information are integrated into their own writing to avoid plagiarism.
\end{abstract}

Keywords: Source-based academic writing, paraphrasing, summarizing, plagiarism

\section{Introduction}

Research into academic writing in English as a foreign language has addressed its role in improving students' writing performance, particularly including how source texts are integrated into writing at tertiary levels (Alhojailan, 2015; Morley-Warner, 2010; H.B. Nguyen, Ho, \& Nguyen, 2019).Thus, in order to write academically, students need good command of English and clarity of what, how, and why of their own writing and to invest their time, effort, and energy to convey and communicate ideas to academic audience. In other words, in college writing, students are encouraged to complete their assignments, namely explaining, reporting, evaluating, synthesizing, interpreting, and reflecting (Fulwiler, 2002). However, in the context of teaching and learning in Vietnam, research into academic writing in English or sourcebased writing is still scarce. In particular, there has no research about how students' perceptions and practices of academic writing and source-based writing may help them improve learning in English for Specific Purposes at tertiary levels. This paper therefore examines how students practiced and perceived academic writing from source texts through paraphrasing and summarizing tasks.

\section{Literature Review}

\subsection{Academic Writing}

There is a growing interest in how academic writing influences student learning outcomes in their English language learning (e.g., Morley-Warner, 2010). There are several views of academic writing in the literature. Academic writing is viewed as a sophisticated blend of generating and selecting ideas to produce a give text (Torrance, Thomas, \& Robinson, 1994). Another view is that academic writing is related to producing and thinking how to communicate knowledge of a specific subject or discipline through a set of rules, requirements, or features to audience (Greane \& Lidnrky, 2012; Oshima \& Hogue, 2007). These conceptualizations suggest that academic writing serves as a guide that contributes to students' academic success or writing competencies in their learning process at college or university.

\subsection{Source-Based Writing}

Writing from sources are widely advocated as making teaching and learning of academic content communicative and authentic at tertiary education (e.g., Gholami \& Alinasab, 2017; Kyle \& Crossley, 2016). Source-based writing is defined as the process of understanding a source or original text and then integrating its relevant content into one's own text through some features of writing, including paraphrasing and summarizing (Davis, 2013). Thus, it is important to note that students should know how to synthesize information from different sources while producing texts with appropriate in-text citations. The relevant way to generate a particular source is citation of the source while writing papers or reviewing the literature of a scientific research. According to Nguyen and his colleagues (2019), there are three most important reasons for the practice of academic writing. First, citation refers to the acknowledgement of all sources used in 
individuals' papers. Second, this practice indicates how primary or original source of reference materials are located to avoid plagiarism. Third, citation demonstrates how individual work or writing product is verified.

\subsection{Paraphrasing}

In academic writing at higher education, it is important to note how source texts are integrated into one's own writing. Paraphrasing is seen as a strategy of putting ideas given in a specific text passage in a different way without changing the meaning of the original text passages (H.B. Nguyen et al., 2019). These authors further indicate that paraphrasing does not mean to substitute words by synonyms. Rather, source texts should be written in a different structure, as noted in the literature (e.g., Blanpain, 2006). In doing so, this strategy provides students with an opportunity to find reading easier to comprehend, thereby sharpening their academic writing through their own style or words while retaining the meanings of the source. More importantly, by comparing their own version with the source text, students are more likely to develop their understanding of appropriate use of the source information with acknowledgement of the credit of the author in order to avoid plagiarism in academia.

\subsection{Summarizing}

Summarizing, like paraphrasing, is a strategy used to select the most important part of source information. It therefore helps students retain important ideas generated from a text (H. B. Nguyen \& Nguyen, 2017). Likewise, Friend (2001)claims that "to make a good summary, a student must be able to relate new ideas with old ones and put unique ideas forward" (p.320). His view suggests that a summary written by students' own words must be short and concise and that this shortened or simplified version provides students with an opportunity to make sense of the information read or rewritten as well as retain it long.

Another perspective on summarizing information is that readers not only recap the text after reading but also design their own texts from what they read (Fountas \& Pintell, 2001). It can be inferred that a reader must be able to analyze, comprehend the information and get across the writer's intentions or messages. Summarizing involves identifying ideas and refining statements of important concepts from a reading text, either in oral or written forms. It may encourage deeper engagement with a text and encourage students to reread as they construct a summary (Kamil, 2004). Nguyen and Nguyen (2017)contend that summarizing, a learning strategy, is a sophisticated process as it demands students to distinguish between main to lesser ideas in a new shortened version from the original text.

The above mentioned literature indicates that source-based writing such as paraphrasing and summarizing play an indispensable role in facilitating students' integration of source materials into their own ways of writing appropriately. However, there have been no studies on the perceptions of students about these two writing strategies within the context of learning English as a foreign language in ESP classes. This paper, therefore, fill such a gap in the literature with regard students' writing performance.

\section{The Study}

A mixed methods approach including quantitative and qualitative data was used to explore students' perceptions about academic writing or source-based writing through paraphrasing and summarizing. This design was considered most appropriate for gaining accurate and valid information and better understanding of the research topic(Creswell, 2012; Fraenkel, Wallen, \& Hyun, 2012).

Questionnaires, test, and interviews were used in this study. Questionnaires were used to examine participants' perceptions about academic writing with a particular regard to source-based texts, paraphrasing and summarizing, and plagiarism. The twenty-four item questionnaire was organized into five aspects. The first aspect focuses on participants' understanding of writing from sources (items 1-7). The second aspect is aimed at examining the conceptualizations of writing from sources (items 8-11). The third aspect centers on the benefits of good writing skills, namely paraphrasing and summarizing (items 12,13, 17 and 18). The four aspect refers to the quality of writing from sources (items 14, 15, $16,19,20,21)$. The fifth aspect is about the challenges of writing from sources (items $23 \& 24$ ). The test on paraphrasing and summarizing was used to investigate participants' actual practices of these two writing strategies. At the end of the study, students were interviewed in the form of focus-group interview to share their views of the benefits, challenges, and expectations while learning writing, namely the above-mentioned aspects.

The study reported in this paper took place over one semester period during the academic year 2019-2020. The focus of this study was to improve the quality of learning foreign languages, namely English and particularly students' academic writing performance for students in ESP classes through the implementation of paraphrasing and summarizing strategies, which responds to the university's major priorities (University Annual Report, 2010). Moreover, the focus of the study was advanced-level economic classes since it is of paramount importance for curriculum developers and ESP teachers to tailor their own teaching materials or syllabi for effective teaching in academic writing. For this study, it was identified that teachers in this field needed to get insights into how economic students majoring in International Trade learn academic writing in English, and then find out ways to help them improve their academic writing, namely sourcebased writing.

\section{Participants}

Seventy-two English non-major sophomores at College of Economics at a university in the Mekong Delta, Vietnam participated in the study. Their age range is from 20 to 21 (28 males, and 44 females). The rationale for this participant selection is that these students are of similar level of English language ability and background. They had studied general (Basic) English and took the entrance exams of English language proficiency or competency before learning English for 
International Trade. Thus, they were qualified with the four English language skills (listening, speaking, reading, and writing) on a basic level to meet the ESP requirements. To protect identities, all names used in this paper are pseudonym.

Twelve students (four high-achieving, four good-achieving, and four average achieving) were selected to the interviews. Semi-structured interviews were used, beginning with open-ended questions, followed by prompts, as indicated by Drever(1997) and Gillham(2005). These interviews were to obtain insights into students' perceptions about academic writing in relation to paraphrasing and summarizing to avoid plagiarism over the writing course. Each interview took place approximately half an hour.

\section{Data Analysis}

The quantitative data collected from the questionnaire were statistically analyzed using the computer software SPSS (Statistical Package for the Social Sciences). The test on paraphrasing and summarizing was analyzed using the VSTEP (Vietnamese Standardized Test of English Proficiency) criteria for grading writing. Four criteria for marking a student's writing performance include task fulfilment, organization, vocabulary, and grammar. However, in this study, these four criteria are delineated by six criteria: task fulfilment, organization (sentence structure), citation, spelling, punctuation, and vocabulary. The rubric is weighted using a five-point Likert-scale for each criterion ( $1=$ poor; $2=$ average; $3=$ fair, $4=$ good, $5=$ excellent).

All interview responses were recorded, transcribed, and translated from Vietnamese into English. The data were analyzed using thematic analysis (Boyatzis, 1998).

\section{Findings}

This section presents the findings of the study with regard to students' perceptions about academic writing from sources and their practices through paraphrasing and summarizing.

\subsection{Students' Perceptions about Source-Based Academic Writing}

\begin{tabular}{|c|c|c|c|c|}
\hline $\mathrm{n}=72$ & Mean & SD & Min & Max \\
\hline $\begin{array}{l}\text { Q1 Writing from source (WFS) is understanding a source text integrated into } \\
\text { one's own text through paraphrasing and summarizing. }\end{array}$ & 3.88 & 0.77 & 2 & 5 \\
\hline Q2 I think WFS is related to word flexibility. & 3.97 & 0.94 & 1 & 5 \\
\hline $\begin{array}{l}\text { Q3 I understand that WFS requires background knowledge of a particular } \\
\text { field. }\end{array}$ & 3.97 & 0.84 & 1 & 5 \\
\hline Q4 I think WFS is synthesis of information in a simplified way. & 3.64 & 0.73 & 2 & 5 \\
\hline Q5 I think WFS reflects understanding of the message in a critical way. & 3.63 & 0.81 & 2 & 5 \\
\hline $\begin{array}{l}\text { Q6 I think WFS requires students to think how to convey key ideas in a } \\
\text { meaningful way. }\end{array}$ & 3.74 & 0.89 & 1 & 5 \\
\hline $\begin{array}{l}\text { Q7 I think WFS is a simplified way to communicate ideas from background or } \\
\text { learned knowledge. }\end{array}$ & 3.61 & 0.94 & 1 & 5 \\
\hline $\begin{array}{c}\text { Q8 I think WFS is another way to put a given text in a clearly organized } \\
\text { structure. }\end{array}$ & 3.48 & 1.00 & 1 & 5 \\
\hline $\begin{array}{c}\text { Q9 I think WFS is a way to restate ideas without changing meanings from the } \\
\text { original text. }\end{array}$ & 3.94 & 0.89 & 1 & 5 \\
\hline $\begin{array}{c}\text { Q10 I think WFS is reading-to-writing process that fosters students' own } \\
\text { writing skill in a logical way. }\end{array}$ & 3.90 & 0.83 & 2 & 5 \\
\hline $\begin{array}{l}\text { Q11 I think WFSis presenting specific information in a communicative and } \\
\text { clear-cut way together with appropriate citation. }\end{array}$ & 3.92 & 0.94 & 2 & 5 \\
\hline Q12 I am self-confident with my paraphrasing skill & 2.58 & 0.80 & 1 & 4 \\
\hline Q13 I am self-confident with my summarizing skill. & 2.71 & 1.00 & 1 & 5 \\
\hline Q14 I know the reliable source for my assignment. & 2.91 & 1.03 & 1 & 5 \\
\hline Q15 I think mastering WFS allows me to avoid plagiarism. & 4.02 & 0.94 & 1 & 5 \\
\hline $\begin{array}{c}\text { Q16 I think mastering WFS enables me to use knowledge to support my } \\
\text { argument. }\end{array}$ & 4.00 & 1 & 1 & 5 \\
\hline Q17 I think mastering WFS enables me to gain good marks in writing. & 3.33 & 0.92 & 1 & 5 \\
\hline $\begin{array}{l}\text { Q18 I think mastering WFS enables me to gain good grade point average } \\
\text { (GPA). }\end{array}$ & 3.38 & 0.86 & 1 & 5 \\
\hline Q19 When writing, I usually read a lot from various sources for ideas. & 3.77 & 1.00 & 1 & 5 \\
\hline $\begin{array}{l}\text { Q20 When writing, I usually think of my own ways, and find sources to make } \\
\text { it academic. }\end{array}$ & 3.42 & 3.60 & 1 & 5 \\
\hline Q21 I know the quality of online and print sources for my writing. & 2.87 & 0.99 & 1 & 5 \\
\hline Q22 I am confident that I can reference (cite) the source accurately. & 2.8 & 1.06 & 1 & 5 \\
\hline Q23 I find it difficult to express source content in my own words. & 3.3 & 1.0 & 1 & 5 \\
\hline $\begin{array}{l}\text { Q24 Due to workload pressure, I sometimes copy from source texts without } \\
\text { acknowledgement. }\end{array}$ & 3.2 & 1.0 & 1 & 5 \\
\hline
\end{tabular}

Table 1: Students' Perceptions about Writing from Source 
Table 1 shows that the overall mean value of a majority of variables, except Qs12, 13, 14, 21, and 22 is above 3.2, indicating that students perceived writing from source at a high level of five-point scale. In particular, students acknowledged the importance of mastering writing from source that allows them to avoid plagiarism $(\mathrm{M}=4.02, \mathrm{SD}=.94)$ and to help them use their own knowledge to support their argument $(M=4.0, S D=.1 .0)$. As a result of their conceptualization of the meaning of writing from source as using their own words without changing meaning of the original source $(\mathrm{M}=3.94, \mathrm{SD}=.89)$ through paraphrasing and summarizing $(\mathrm{M}=3.88, \mathrm{SD}=.77)$, students were aware of the vital role of word flexibility $(\mathrm{M}=3.97, \mathrm{SD}=.94)$ and background knowledge $(\mathrm{M}=3.97, \mathrm{SD}=.84)$ while writing. Likewise, students recognized the quality of writing from source with regard to improved structure and logical writing $(\mathrm{M}=3.90, \mathrm{SD}=$ .83) as well as communicative and clear way together with appropriate citation of the source text $(\mathrm{M}=3.92, \mathrm{SD}=.0 .94)$. With regard to academic writing success, students perceived that mastery of writing from source would allow them to gain satisfactory scores in writing assignments $(\mathrm{M}=3.33, \mathrm{SD}=.92)$ and in their end-of the writing course $(\mathrm{M}=3.38, \mathrm{SD}=$ .86).However, the mean scores of students' feeling of confidence in paraphrasing, summarizing, and searching for reliable sources for written assignments were at low level, a little above average in the five-point Likert scale respectively ( $\mathrm{M}=2.58$, $\mathrm{SD}=.80),(\mathrm{M}=2.71, \mathrm{SD}=1.0),(\mathrm{M}=2.91, \mathrm{SD}=1.03)$.Specifically, descriptive statistics test indicates that students did not know the quality of online and print sources and that they lacked confidence in in-text citation $(\mathrm{M}=2.87, \mathrm{SD}=.99)$ or reference of sources $(\mathrm{M}=2.8, \mathrm{SD}=1.06)$.

\subsection{Students' Writing Performance in Paraphrasing and Summarizing}

Table 2 describes the results of academic writing assessment through paraphrasing and summarizing. Regarding students' writing performance in paraphrasing, students gained an overall score below $2.6(\mathrm{M}=2.59, \mathrm{SD}=0.66)$ and ofthe six criteria, citation was recorded as low $(\mathrm{M}=1.64, \mathrm{SD}=1.06)$. However, it was found that students scored high in the criterion of task fulfilment $(\mathrm{M}=3.11, \mathrm{SD}=1.01)$. Likewise, with regard to students' writing performance in summarizing information, students fulfilled the task at a relatively high level $(\mathrm{M}=3.18, \mathrm{SD}=0.77)$, whereas, they did not do well on sentence structure $(\mathrm{M}=1.59, \mathrm{SD}=1.21)$.

\begin{tabular}{|c|c|c|c|c|c|c|c|c|}
\hline \multirow{2}{*}{$\mathbf{n = 7 2}$} & \multicolumn{4}{|c|}{ Paraphrasing } & \multicolumn{4}{c|}{ Summarizing } \\
\cline { 2 - 9 } & Mean & SD & Min & Max & Mean & SD & Min & Max \\
\hline Task fulfillment & 3.11 & 1.01 & 1 & 5 & 3.18 & 0.77 & 1 & 4.5 \\
\hline $\begin{array}{c}\text { Organization } \\
\text { (Sentence structure) }\end{array}$ & 2.65 & 0.73 & 1 & 5 & 1.59 & 1.21 & 1 & 5 \\
\hline Citation & 1.64 & 1.06 & 1 & 5 & 2.44 & 0.79 & 1 & 5 \\
\hline Spelling & 3.02 & 0.75 & 1 & 5 & 2.83 & 0.66 & 1 & 5 \\
\hline Punctuation & 2.76 & 0.83 & 1 & 5 & - & - & - & - \\
\hline Vocabulary & 2.34 & 0.75 & 1 & 4 & 2.88 & 0.63 & 1 & 5 \\
\hline Overall & 2.59 & 0.66 & 1 & 4.8 & 2.58 & 0.56 & 1 & 4.4 \\
\hline
\end{tabular}

Table 2: Results of Students' Paraphrasing and Summarizing Performance

\subsection{Insights into Students' Perceptions about Academic Writing in English}

Interview data reveal that all of twelve students perceived academic writing in English as a type of formal writing that is designed for a particular subject matter. The six extracts below illustrate their views.

- I think academic writing refers to a writing style that is formal and scientific (Mai, interview extract)

- Well, academic writing is logic way of presenting something in a subject specific area of expertise (Lan, interview extract)

- Before learning this writing course, I have no idea of what academic writing is. However, now I know that this style is important as this helps me move to a formal level or think of the intended audience, namely the use of particular words in a given type of texts (Truc, interview extract).

- Academic writing is for specialized area of study. In addition, vocabulary is used in technical field or area(Son, interview extract).

- Academic writing involves technical terms used in particular field or science, or thesis writing, in a clear, concise, and formal way (Hai, interview extract).

- Academic writing is associated with academic work like that in university for intended audience. It also relates to other areas of study at a higher level of formality, technical terms in specific discipline (Tin, interview extract).

\subsection{Conceptualizations of the Importance of Academic Writing}

Four students revealed that academic writing was useful and important as this type of writing moved them forward their thinking and enhanced their command of English language use. Their views are illustrated in the following extracts.

\subsubsection{Insights into Students' Understanding of Academic Writing}

- I think academic writing helps me improve writing skill. In particular, the vocabulary use, formality of writing, context, and grammar structure are all connected (Thy, interview extract). 
- Academic writing as I understand is about the organization of a text, paragraph, or essay at college or university study. This writing style is somewhat having formal or polishing one to be read by teacher or instructor, or expert of a subject specific (Nhung, interview extract).

- Well, academic writing is seen as writing something related to a field of study and it must be objective and scientific. Vocabulary and structure are built up or accumulated over time (Dang, interview extract).

- I think academic writing is different from other writing in ways that the choice of words is for whom and that any ideas or implications are figured out. For example, technical words or specialized terms are appropriately used in particular tasks. Citing or referencing the source is an example for academic writing (Thao, interview extract).

These above quotes suggest that students thought academic writing is an interactive learning process that mainly focuses on how words and ideas or concepts are intertwined. So, citing the source is what academic writing demands or requires of learners.

\subsubsection{Feeling of Confidence}

Four students revealed that academic writing was beneficial as this type of practice brought them feeling of confidence. They stated:

- Conceptually speaking, there is almost no change in what academic writing is. However, since the beginning of university study, I had an opportunity to use what is called academic writing from ESP class in relation to international trade. Particularly, I understand how academic writing in English benefits my way of learning and then I feel more confident in my writing style using correct grammar and more complex structures in an appropriate context (Thao, interview extract)

- I think after learning how to paraphrase or summarize information given in a text of international trade, I can understand what is needed to do and the responsibility for the cited source or the contribution of the writer he or she made. Now, I write better by using my own words (Lan, interview extract)

- I feel confident indeed as acknowledging the work of others (Cuc, interview extract).

- Vocabulary, background knowledge I used in paraphrasing or summarizing statements provided me with chances to practice English easier. I think I understand better (Truc, interview extract).

- These above quotes suggest that students believed that academic writing, particularly through using their own words to restate others' ideas, is related to students' awareness of what is needed to do when citing the source text or information.

\subsubsection{Students' Sense of Plagiarism in Relation to Agency}

Before we study this writing course, namely how to paraphrase or summarize statements, we did not have any idea of what plagiarism is. Since we learn to cite the source information, we think it is not good to copy others' work (Tin, interview extract)

- I find it difficult to avoid repetition of words or information used by the others as I lack vocabulary or related words with similar meanings as required by the teacher. As a student, it is very easy to cheat in writing of any type when having to complete assignments, particularly home assignment given by the teacher. However, over time I know copying others' work without giving credit to them is a shame (Hung, interview extract).

- I want to say that for the first two years at university we have not learnt how to use own words or what to do to avoid what is called plagiarism. No teacher told us to write what is accepted or unacceptable until we were taught how to cite the source text to respect the work of others. Since I attempted to express something on my own in writing, I realize it is so bad and unfair with others if I did something wrong( Cuc, interview extract).

- The above quotes indicate that students perceived plagiarism as an ethical issue at college writing. Their reference to the students' responsibility for their own writing from sources was associated with their sense of agency in their learning process. Their self-reports also reveal that plagiarism is what students should avoid.

\subsubsection{Challenges in Writing from Sources}

Three students revealed that two challenges they encountered while learning academic writing or source-based writing include vocabulary and structure change. They stated:

- Lack of vocabulary while doing a paraphrasing exercise may confuse me and take time. Finding words to replace the ones in the source text passage is not easy at all. To put ideas in a different structure to avoid repetition is hard, too. (Lan, interview extract)

- It is quite new and difficult to us to think of some words to substitute others given in a source text. Sometimes finding the way to change the original statement or sentence given in a short passage is something that beyond our ability and language use (Hung, interview extract).

- As I have little vocabulary at the beginning of the course, I sometimes neither have ideas of what word can be used to rewrite just two sentences or summarize them nor use a different grammatical structure(Hung, interview extract).

\section{Discussion}

The findings of the study indicate that the participating students perceived the value of academic writing and source-based writing as formal style designed specifically for a subject specific matter with regard to paraphrasing and summarizing strategies. These students also realized that academic writing through the use of these above two strategies was beneficial since it results in their forward thinking, improved English language use, and increased feeling of 
confidence. This supports the claim that source based writing abilities with the main focus of paraphrasing and summarizing allow students to improve writing competence (Gholami \& Alinasab, 2017; McDonough, Crawford, \& Vleeschauwer, 2014). However, students could not do well on the test of these two aspects. In particular, students' scores in citing sources under average level suggest the real challenge that students may be vulnerable to plagiarism while learning writing(Ansas \& Sukyadi, 2019; Pecorari, 2003). In this regard, it appears that students could have failed to practice writing by using their own words or to understand the meaning of plagiarism while developing their ideas to complete a given writing task. Likewise, as far as the summarizing strategy is concerned, students got lower than average scores on citation and the use of sentence structure (organization of ideas). Specifically, students' lack of ability to cite a given source text and possess insufficient knowledge of sentence structure in order to make changes in writing their own need to consider.

The findings reveal positive perceptions reported by twelve students towards source-based writing and plagiarism in their writing class, which is consistent with Davis' (2013)study which indicated that students understood how academic writing through paraphrasing and summarizing work. Specifically, students perceived plagiarism as an ethical issue or misconduct at college contexts. Their conceptualizations of plagiarism are linked with their sense of agency in the learning process. Their agency refers to the way they are responsible for writing by using their own words and giving the credit of author's work. This is consistent with other studies (Fish \& Hura, 2013; Power, 2009) which address that plagiarism is a real concern at university education and that desire to achieve agency is meaningful and worth communicating while completing a given writing assignment. However, insufficient vocabulary and structure change were the challenges students reported while learning or completing the writing tasks. Once students became more aware of their agency and understood how to deal with challenges, they are more likely to realize that plagiarism should be avoided while developing their own ideas and refining source-based writing in the long run.

\section{Conclusions}

The findings have shed light on academic writing and source-based writing through paraphrasing and summarizing strategies practiced and perceived by students. Notably, pedagogical implications for both teachers and students are presented. The study could raise students' awareness of their own writing styles; all of which incorporated into their lessons but also for other aspects of English language skills, namely vocabulary and grammatical structures. There is a pressing need for teachers to guide students to practice more citations of source text by making best use of their time and efforts at libraries or learning resources centers to read, find appropriate references for their own writing assignments, and write their own basing on these resources. Further research should focus on students' understanding of the importance of using their own words or ideas instead of copying or using ideas or work from the author's work without citing the source information. More studies with a larger sample size within a longer time periods are needed to provide an overview of the value of source-based writing while preventing students from committing plagiarism.

\section{References}

i. Alhojailan, A. (2015). Perceptions of academic writing by some Saudi graduate students studying in American universities. (PhD), Oklahoma State University, Oklahoma, USA.

ii. Ansas, V. N., \& Sukyadi, D. (2019). Source-based writing among undergraduate students: Students' perpective and challenges. International Journal of Education, 11(2), 152-157.

iii. Blanpain, K. (2006). Academic writing in the humanities and social sciences: A resource for researchers: Acco.

iv. Boyatzis, R. E. (1998). Transforming qualitative information: Thematic analysis and code development Thousand Oaks, California: SAGE Publications, Inc.

v. Creswell, J. W. (2012). Educational research: Planning, conducting, and evaluating quantitative and qualitative research (4th Ed.). Boston, MA: Pearson Education, Inc.

vi. Davis, M. (2013). The development of source use by international postgraduate students. Journal of English for Academic Purposes, 12(2), 125-135.

vii. Drever, E. (1997). Using semi-structured interviews in small scale research: A teacher guide. Glasgow: Scottish Council for Research in Education.

viii. Fish, R., \& Hura, G. (2013). Students' perceptions of plagiarism. Journal of the Scholarship of Teaching and Learning, 13(5), 33-45.

ix. Fountas, I. C., \& Pintell, G. S. (2001). Guiding readers and writers Grades 3-6: Teaching comprehension, genre, and content literacy: Pearson Education, Canada.

x. Fraenkel, J. R., Wallen, N. E., \& Hyun, H. H. (2012). How to design and evaluate research in education (8th Ed.). New York: McGraw-Hill Humanities.

xi. Friend, R. (2001). Effects of strategy instruction on summary writing of college students. Contemporary Educational Psychology, 26(1), 3-24.

xii. Fulwiler, T. (2002). College writing: A personal approach to academic writing (3rd Ed.): Boynton/ Cook Publishers, Inc.

xiii. Gholami, J., \& Alinasab, M. (2017). Source-based tasks in writing independent and integrated essays. International Journal of Instruction, 10(3), 127-142.

xiv. Gillham, B. (2005). Research interviewing: The range of techniques. New York, NY: Open University Press.

xv. Greane, S., \& Lidnrky, A. (2012). From inquiry to academic writing: A text and reader. Boston, MA: Bedford/ St. Martin. 
xvi. Kamil, M. L. (2004). Vocabulary and comprehension instruction: Summary and iimplications of the National Reading Panel findings. In P. McCardle \& V. Chhabra (Eds.), The voice of evidence in readiing research. Baltimore, MD: Paul H. Brookes.

xvii. Kyle, K., \& Crossley, S. (2016). The relationship between lexical sophistication and independent and source-based writing. Journal of Second Language Writing, 34, 12-34.

xviii. McDonough, K., Crawford, J. W., \& Vleeschauwer, D. J. (2014). Summary writing in a Thai EFL university context. Journal of Second Language Writing, 24(1), 20-32. doi: https:/ / doi:10.1016/ j.jslw.2006.09.004

xix. Morley-Warner, T. (2010). Academic writing is: A guide to writing in a university context. NSW, Australia: AALL (Association for Academic Language and Learning).

xx. Nguyen, H. B., Ho, T. P., \& Nguyen, T. T. N. (2019). Advanced writing skills II (2nd Ed.). Can Tho: Can Tho University Pulbishing House.

xxi. $\quad$ Nguyen, H. B., \& Nguyen, N. T. K. (2017). Summarizing strategies: Potential tool to promote English as a foreign language (EFL) students' reading comprehension at a vocational school, Vietnam. European Journal of Education Studies, 3(8), 51-72.

xxii. Oshima, A., \& Hogue, A. (2007). Introduction to academic writing. New York: Pearson.

xxiii. Pecorari, D. (2003). Good and original: Plagiarism and patchwriting in academic second language writing. Journal of Second Language Writing, 12, 317-345. doi: http;// dx.doi.org/ 10.1016/ j.jslw.2003.08.004

xxiv. Power, L. G. (2009). University students' perceptions of plagiarism. The Journal of Higher Education, 80(6), 643662.

xxv. Torrance, M., Thomas, G. V., \& Robinson, E. J. (1994). The writing strategies of graduate research students in the social sciences. Higher Education, 27(3), 379-392.

xxvi. University Annual Report. (2010): Can Tho. 